\title{
Réplica
}

\section{Em defesa de Brenno Silveira}

Denise Bottmann*

A revista Domínios de Linguagem dedicou seu último número (v. 5, n. 3, 2011, disponível online) à atividade de tradução. Entre os artigos encontra-se "Edgar Poe em português: limites entre tradução e adaptação", da autoria de Élida Paulina Ferreira e Karin Hallana Santos Silva.

Sem pretender me deter nos indiscutíveis méritos do artigo, faço inicialmente alguns pequenos esclarecimentos fatuais:

- As traduções de Brenno Silveira analisadas pelas articulistas saíram inicialmente em 1959, numa coletânea que ele próprio selecionou e traduziu, publicada pela editora Civilização Brasileira com o título de Antologia de Contos de Edgard Allan Poe, dado este que não consta do referido artigo.

- Apenas em 1970, a Civilização Brasileira altera o título dessa coletânea para Histórias Extraordinárias, que então se manteve por várias décadas em seus licenciamentos para o Círculo do Livro, a Abril Cultural e a Nova Cultural, até data recente, quando a mesma coletânea foi reeditada pela Best Bolso com o título de Antologia de contos extraordinários, com a devida menção à responsabilidade de Brenno pela seleção dos contos.

- A identificação entre Tales of the Grotesque and Arabesque e Histórias Extraordinárias não passa de um tolo despautério editorial perpetrado pela Abril Cultural em 1978, que acabou se alastrando para outras edições e gerando alguns graves equívocos. Sobre o histórico do uso do título Histórias Extraordinárias no Brasil desde 1958 (pela Cultrix, na coletânea selecionada e traduzida por José Paulo Paes) e os descaminhos pelos quais enveredou a partir de 1978, pode-se

\footnotetext{
* Historiadora, tradutora, ex-docente do Depto. Filosofia da Unicamp.
} 
consultar meu artigo, "Alguns aspectos da presença de Edgar Allan Poe no Brasil", em esp. seção IV. ${ }^{1}$

I.

O reparo mais importante que tenho a fazer sobre o artigo de Élida Ferreira e Karin Silva, porém, diz respeito aos exemplos apresentados como provas de acréscimos, omissões e outras alterações. Comecemos pelos supostos acréscimos que Brenno Silveira (1959) teria feito ao texto original de Edgar Allan Poe, no conto "Berenice":

Nesse âmbito, ... também observamos acréscimos de trechos. Quando o tradutor opta por acrescentar algo à tradução que não consta no original, ele amplia de forma a trazer mais elementos interpretativos, interferindo na recepção do texto e, eventualmente, criando uma imagem diferente desse texto na língua de chegada. (p. 26 , negritos meus)

O exemplo dado como acréscimo de um trecho "que não consta no original" é o seguinte, às pp. 26-7 (em destaque meu):

Poe: I held them in every light - I turned them in every attitude. I surveyed their characteristics - I dwelt upon their peculiarities - I pondered upon their conformation - I mused upon the alteration in their nature - and shuddered as I assigned to them in imagination a sensitive power, and even when unassisted by the lips, a capability of moral expression. Of Mad'selle Sallé it has been said, 'que tous ses pas etaient des sentiments', and of Berenice I more seriously believed que tous ses dents etaient des idées.

Silveira: Via-os sob todos os aspectos; revolvia-os em todos os sentidos; estudava suas características. Refletia longamente sobre suas peculiaridades. Meditava sobre sua conformação. Cogitava acerca de sua natureza. Estremecia ao atribuir-lhes, em minha imaginação, uma

\footnotetext{
${ }^{1}$ Quanto à fortuna histórica dessa coletânea organizada por Brenno Silveira em 1959, e originalmente publicada com o título de Antologia de contos de Edgar Allan Poe, pela editora Civilização Brasileira, veja-se meu artigo, "Alguns aspectos da presença de Edgar Allan Poe no Brasil", in Contribuições para uma Historiografia da Tradução, PUC-RJ, Tradução em Revista, 8, 2010/1, p. 01-19, disponível em http://www.maxwell.lambda.ele.puc-rio.br/trad_em_revista.php?strSecao=input0.
} 
faculdade de sensação e de sensibilidade e, mesmo quando não ajudados pelos lábios, uma capacidade de expressão moral. De Mademoiselle Sallé foi dito - aliás muito bem - que 'tous ses pás étaient des sentiments', e, de Berenice, eu acreditava ainda mais seriamente que toutes ses dents étaient des idées! Des idées!- ah! Aqui estava o pensamento idiota que me destruiu! Des idées! -Ah era por isso que eu os cobiçava tão loucamente! Sentia que somente a posse deles poderia restituir-me a paz, fazendo-me recobrar a razão."

Seria de fato surpreendente que Brenno, um dos tradutores mais cuidadosos e atentos à letra e ao sentido das obras que traduzia, tivesse acrescentado à sua tradução tal extenso trecho apenas a título de "comentário interpretativo", como afirmam as autoras à p. 27.

Na verdade, a questão é bem mais simples. Trata-se apenas de duas versões diferentes de "Berenice": as autoras tomaram como referência a versão de 1835, reproduzida na edição das $T G A$ de 1840, ao passo que Brenno Silveira, para sua seleção e tradução do conto, utilizou a versão definitiva, estabelecida por Poe desde $1845 .^{2}$ Veja-se a versão final do texto de Poe (negrito meu):

I held them in every light. I turned them in every attitude. I surveyed their characteristics. I dwelt upon their peculiarities. I pondered upon their conformation. I mused upon the alteration in their nature. I shuddered as I assigned to them in imagination a sensitive and sentient power, and even when unassisted by the lips, a capability of moral expression. Of Mademoiselle Sallé it has been well said, "Que tous ses pas etaient des sentiments," and of Berenice I more seriously believed que tous ses dents etaient des idées. Des idées! - ah here was the idiotic thought that destroyed me! Des idées! - ah therefore it was that I

\footnotetext{
${ }^{2}$ Aos interessados na obra de Poe, recomendo o trabalho fenomenal, do mais rigoroso scholarship, desenvolvido pela Edgar Allan Poe Society of Baltimore, que pode ser consultado no site http://www.eapoe.org. Para as informações relativas a "Berenice" e a "Metzengerstein", com seus históricos e várias versões, consultem-se respectivamente http://www.eapoe.org/works/info/pt011.htm e http://www.eapoe.org/works/info/pt005.htm. Cabe dizer que as articulistas chegam a citar este site em sua bibliografia, mas aparentemente preferiram se deter apenas numa das versões.
} 


\section{coveted them so madly! I felt that their possession could alone ever restore me to peace, in giving me back to reason.}

Em suma, o tradutor não procedeu a qualquer acréscimo ou comentário interpretativo a esta passagem: o acréscimo fora feito pelo próprio autor, Edgar Allan Poe, na versão definitiva de "Berenice", ela sim utilizada por Brenno Silveira em sua tradução.

II.

Ademais, ainda segundo o mesmo artigo, Brenno Silveira teria ferido "o princípio de fidelidade" e "quebra[do] a atmosfera de suspense e mistério" do conto "Metzengerstein", de Poe, devido à "supressão" de vários trechos do original em sua tradução. De mais a mais, o tradutor teria alterado a idade do protagonista, a determinada altura dos fatos, de quinze para dezoito anos.

Não transcreverei aqui os trechos supostamente suprimidos, pois basta comparar as versões no cânone poeano para constatar que as mudanças foram feitas pelo próprio autor. Detenho-me apenas no breve trecho em que Brenno teria alterado a idade do protagonista, citado às pp. 25-26 do referido artigo:

Frederick was, at that time, in his fifteenth year. In a city fifteen years are no long period - a child may be still a child in his third lustrum: but in a wilderness - in so magnificent a wilderness as that old principality, fifteen years have a far deeper meaning.

Frederick contava, a essa altura, dezoito anos. Numa cidade, dezoito anos não são muito tempo; mas na solidão - numa solidão tão magnífica como a daquele velho principado - o pêndulo vibra com um significado mais profundo.

As articulistas interpretam tal discrepância como resultado de uma opção deliberada de Brenno, ${ }^{3}$ com vistas a adaptar o original ao contexto brasileiro, onde se

\footnotetext{
${ }^{3}$ E de Clarice Lispector também, com sua adaptação tratada em paralelo com a tradução de Brenno.
} 
atinge a maioridade aos dezoito anos, ademais suprimindo a frase "a child may be still a child in his third lustrum" para melhor adequar o texto em português a seus propósitos de "contextualização". O veredito é o seguinte:

\begin{abstract}
Essa contextualização, no entanto, implica uma interpretação distinta do original no que concerne à visão que se tem da personagem, uma vez que com quinze anos ele é considerado uma criança e explicaria suas atitudes diante da perda dos pais. Sendo um adulto o fragmento perde todo o sentido em português. [p. 26; negrito meu]
\end{abstract}

Veja-se, porém, o que diz o texto original de Poe, em sua versão definitiva:

Frederick was, at that time, in his eighteenth year. In a city, eighteen years are no long period; but in a wilderness - in so magnificent a wilderness as that old principality, the pendulum vibrates with a deeper meaning. (1850)

Tal como no caso dos supostos acréscimos e do "comentário interpretativo" que Brenno Silveira teria incluído em sua tradução de "Berenice", também aqui, nas alegadas supressões e alterações que ele teria efetuado em sua tradução de "Metzengerstein", o simples fato é que, na verdade, as diferenças resultam da revisão que o próprio autor, Edgar Allan Poe, fez em seu conto. A versão de "Metzengerstein" selecionada e traduzida por Brenno é, evidentemente, a definitiva, tal como consta na edição de 1850, ao passo que as autoras do artigo, ao que tudo indica, limitaram-se a consultar a versão de 1840 .

Feitos tais reparos, que ajudam a esclarecer as discrepâncias apontadas pelas autoras, acrescento por fim uma singela informação, que pode parecer surpreendente a muitos: Tales of the Grotesque and Arabesque, como coletânea de direito próprio, tal como foi concebida e organizada por Edgar Allan Poe, continua absolutamente inédita no Brasil. ${ }^{4}$

Réplica recebida em: 30.03 .2012

Réplica aceita em: 11.05.2012

\footnotetext{
${ }^{4}$ Para dados variados sobre a poeana brasileira, veja-se também http://eapoebrasil.blogspot.com.
} 